(A)

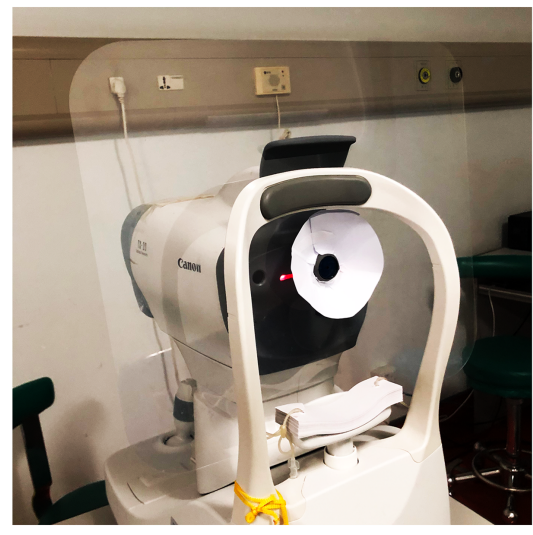

(C) Without paper funnel

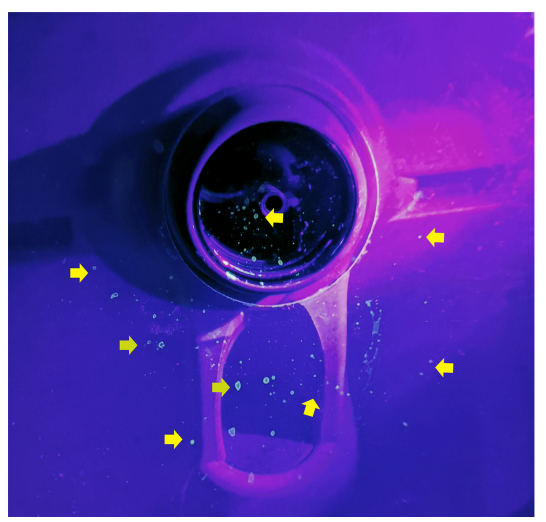

(B)

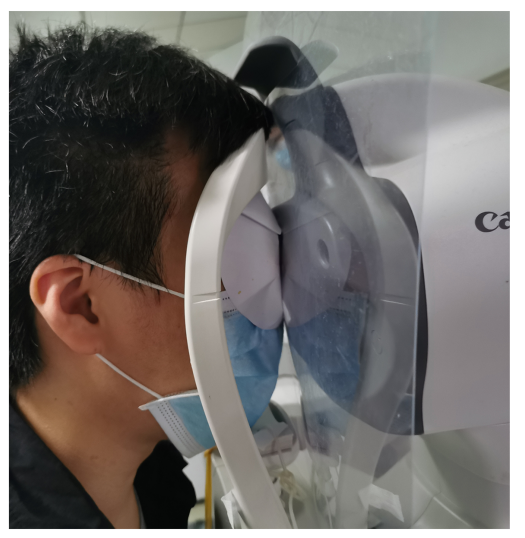

(D) With paper funnel

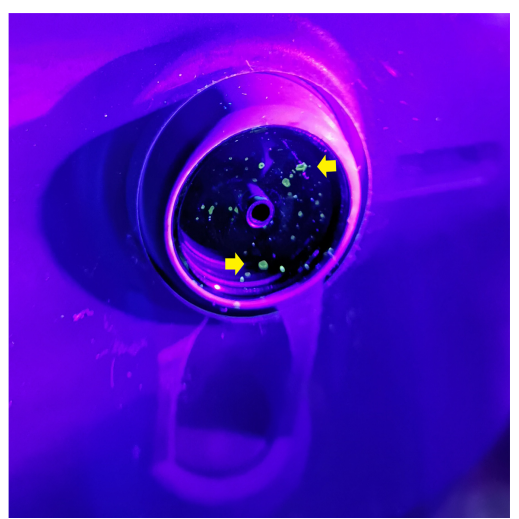

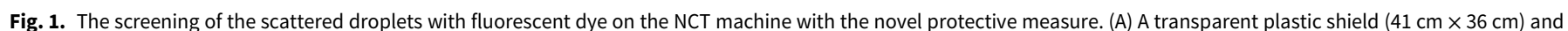
a homemade paper funnel were installed on the NCT machine. (B) The volunteer positioned his head in the chin and forehead rest, and his eye was covered by the funnel. (C) Scattered tear droplets on the shield and sensor with the plastic shield only (yellow arrow). (D) Scattered tear droplets on the sensor with the plastic shield and the paper funnel (yellow arrow).

Conflicts of interest. All authors report no conflicts of interest relevant to this article.

\section{References}

1. Britt JM, Clifton BC, Barnebey HS, Mills RP. Microaerosol formation in noncontact 'air-puff tonometry. Arch Ophthalmol 1991;109:225-228.
2. Colavita F, Lapa D, Carletti F, et al. SARS-CoV-2 isolation from ocular secretions of a patient with COVID-19 in Italy with prolonged viral RNA detection. Ann Intern Med 2020 Apr 17. doi: 10.7326/M20-1176.

3. Xia J, Tong J, Liu M, Shen Y, Guo D. Evaluation of coronavirus in tears and conjunctival secretions of patients with SARS-CoV-2 infection. J Med Virol 2020;92:589-594.

\title{
Inappropriate sales of hypochlorous acid solution in Japan: An online investigation
}

\author{
Satoru Mitsuboshi PhD ${ }^{1}$ (1), Ryo Yamaguchi², Hiroyuki Uchida ${ }^{3}$, Satoshi Kamoshida ${ }^{4}$ and Hideki Hashi ${ }^{5}$ (1) \\ ${ }^{1}$ Department of Pharmacy, Kaetsu Hospital, Niigata, Japan, ${ }^{2}$ Department of Pharmacy, The University of Tokyo Hospital, Tokyo, Japan, ${ }^{3}$ Department of \\ Pharmacy, Kanto Rosai Hospital, Kanagawa, Japan, ${ }^{4}$ Department of Pharmacy, Mito Brain Heart Center, Ibaraki, Japan and ${ }^{5}$ Department of Pharmacy, \\ Tokyo Bay Urayasu Ichikawa Medical Center, Chiba, Japan
}

Author for correspondence: Satoru Mitsuboshi, E-mail: mitsuboshi_s@niigata-min. or.jp

Cite this article: Mitsuboshi S, et al. (2021). Inappropriate sales of hypochlorous acid solution in Japan: An online investigation. Infection Control \& Hospital Epidemiology, 42: 1297-1299, https://doi.org/10.1017/ice.2020.1248
To the Editor-The use of disinfectants has become more widespread due to the spread of severe acute respiratory coronavirus virus 2 (SARS-CoV-2). In particular, chlorine-based disinfectants such as hypochlorous acid solution (HAS) are inexpensive and widely available. The World Health Organization and the US 
Table 1. Inappropriate Sales of Hypochlorous Acid Solution $(\mathrm{N}=97)$

\begin{tabular}{ll}
\hline Variable & No. (\%) \\
\hline Provision of inappropriate product information & \\
\hline Product concentration, no & $30(31)$ \\
\hline Product pH, no & $54(56)$ \\
\hline Product expiration date, no & $54(56)$ \\
\hline Removal of dirt before use of disinfectant, no & $91(93)$ \\
\hline Correct amount to use, no & $91(93)$ \\
\hline Efficacy examination by public institution, no & $97(100)$ \\
\hline Safety examination by public institution, no & $97(100)$ \\
\hline Inappropriate use recommendations & \\
\hline Use by spraying, yes & $91(93)$ \\
\hline Use by direct application onto hands, yes & $39(40)$ \\
\hline Use by fogging of indoor spaces, yes & $58(59)$ \\
\hline Inappropriate advertising & $32(33)$ \\
\hline Use of the word "disinfection," yes & $20(21)$ \\
\hline For use in healthcare facilities, yes
\end{tabular}

Centers for Disease Control and Prevention state that HAS should be used only for products and environmental surfaces and is not suitable for external or internal use by humans or for fogging of indoor spaces. ${ }^{1,2}$ This chlorine gas carries a risk of adverse respiratory system events, even at low levels of exposure. ${ }^{3,4}$ However, adverse events associated with disinfectants have been increasing in the United States since January 2020; 62\% of these were caused by chlorine disinfectants, with inhalation as the main factor. ${ }^{5}$ Accordingly, adverse events related to the inappropriate use of disinfectants may be increasing worldwide.

In May 2020, the Japanese Ministry of Economy, Trade, and Industry warned the public that HAS should not be used for fogging or for direct application onto the hands. ${ }^{6}$ Because the supply of alcohol-based disinfectants began to run low as SARS-CoV-2 spread in Japan, many facilities (eg, nursery schools, elementary schools, railway companies, restaurants, and public institutions) introduced devices to atomize HAS, inappropriately using it to fog indoor spaces or to directly sanitize the hands. Although HAS products have been sold by many companies, these products may have been sold without information on their appropriate use. Here, we investigated the inappropriate sale of HAS by companies in Japan.

We searched the Amazon website (https://www.amazon.co.jp/) for the term "hypochlorous acid solution" on August 1, 2020, and assessed all companies identified. The Amazon website was used to investigate the provision of inappropriate product information, inappropriate use recommendations, and inappropriate advertising. When a company listed its website, we also investigated the site. The details of the items investigated are shown in Table 1. Companies that did not sell HAS products were excluded. We assessed whether efficacy and safety examinations had been performed based on the recommendations of one of several public institutions, including the International Organization for Standardization, Japanese Industrial Standards, the European Committee for Standardization, the American Society for Testing and Materials, or the Association of Official Analytical Chemists. In total, 97 companies were investigated.
Our research revealed that many companies provided inappropriate product information, recommended inappropriate use, and engaged in inappropriate advertising practices. To our knowledge, this is the first report to clarify the inappropriate sale of HAS products. Three concerns regarding efficacy, safety, and hype were raised by these results.

First, the efficacy of many HAS products could not be assessed using standard indicators. For example, $30 \%$ of products had no label information on concentration, and $50 \%$ of products had no label information on $\mathrm{pH}$ or expiration date. In addition, most products did not describe the removal of dirt before the use of the disinfectant and the correct amount to use. Previous reports suggest that the presence of dirt, such as organic matter, and the use of an insufficient amount decrease the effectiveness of chlorine-based disinfectants and that their effectiveness may decrease at 2-4 weeks after the container has been opened. ${ }^{7,8}$ Moreover, it was unclear whether any of the products had undergone standard tests performed by public institutions to determine their safety and efficacy. ${ }^{9}$ HAS products may be useful for preventing the transmission of SARS-CoV-2 when they are used at the appropriate concentration and in the appropriate manner. However, these products may not have been effective for such an application.

Second, these products may cause adverse events. More than $90 \%$ of the products were recommended to be used by spraying, and $\sim 50 \%$ of them were recommended to be used by direct application onto the hands or by fogging of indoor spaces. Chlorine gas has a risk of adverse respiratory system events. ${ }^{3}$ Children, the elderly, and individuals with comorbidities, all of whom have low toxicity tolerance, may be at particularly high risk of adverse events from exposure to chlorine gas resulting from inappropriate use of HAS. ${ }^{3,4}$ Indeed, some adverse events caused by HAS have been reported in Japan, possibly reflecting its inappropriate use. ${ }^{10}$

Third, 33\% of products were advertised using the word "disinfection." The use of the word "disinfection" is allowed only for medications registered under the Pharmaceutical and Medical Device Act in Japan. No HAS products are registered as medications in Japan, and thus such advertisements may be illegal. Moreover, 20\% of the products were advertised for use in healthcare facilities. The reference to healthcare facilities may give people false reassurance concerning the effectiveness of the products and may be a strategy to boost sales. HAS may be inappropriately used in healthcare facilities that lack disinfectant specialists, such as nursing homes, clinics, and dental clinics. Further strategies for the proper use of disinfectants in these facilities may be needed.

Our research has some limitations. Only those companies listing products on the Amazon website were studied; thus, these results need to be confirmed by further research. However, many people use the Amazon website because of its prominence. In addition, because we investigated only those products that contained HAS, other products that were inappropriately advertised were not included in our investigation.

In conclusion, to protect patients and the general public from health hazards associated with the inappropriate use of HAS, it may be necessary to develop and implement appropriate regulations and to conduct awareness campaigns for both healthcare providers and the general public.

Acknowledgments. We thank the members of the Infectious Disease Association for Teaching and Education in Nippon (IDATEN) and the IDATENpharm for their highly insightful advice on this work.

Financial support. No financial support was provided relevant to this article. 
Conflicts of interest. All authors report no conflicts of interest relevant to this article.

\section{References}

1. Interim infection prevention and control recommendations for healthcare personnel during the coronavirus disease 2019 (COVID-19) pandemic. Centers for Disease Control and Prevention website. https://www.cdc. gov/coronavirus/2019-ncov/hcp/infection-control-recommendations.html Published 2020. Accessed September 6, 2020.

2. Cleaning and disinfection of environmental surfaces in the context of COVID-19. World Health Organization website. https://www.who.int/ publications/i/item/cleaning-and-disinfection-of-environmental-surfacesinthe-context-of-covid-19. Published 2020. Accessed September 6, 2020.

3. White CW, Martin JG. Chlorine gas inhalation: human clinical evidence of toxicity and experience in animal models. Proc Am Thorac Soc 2010;7: 257-263.

4. Slaughter RJJ, Watts M, Vale JAA, Grieve JRR, Schep LJJ. The clinical toxicology of sodium hypochlorite. Clin Toxicol 2019;57:303-311.

5. Chang A, Schnall AH, Law R, et al. Cleaning and disinfectant chemical exposures and temporal associations with COVID-19-National Poison
Data System, United States, January 1, 2020-March 31, 2020. Morb Mortal Wkly Rep 2020;69:496-498.

6. Facilities in Japan cautioned against hypochlorous acid misting to fight COVID-19. The Mainichi website. https://mainichi.jp/english/articles/ 20200602/p2a/00m/0na/025000c. Published 2020. Accessed September 6, 2020.

7. Takeda Y, Uchiumi H, Matsuda S, Ogawa H. Acidic electrolyzed water potently inactivates SARS-CoV-2 depending on the amount of free available chlorine contacting with the virus. Biochem Biophys Res Commun 2020; 530:1-3.

8. Gallandat K, Kolus RCC, Julian TRR, Lantagne DSS. A systematic review of chlorine-based surface disinfection efficacy to inform recommendations for low-resource outbreak settings. Am J Infect Control 2020;S0196-6553(20) 30311-4.

9. Tomasino SF. Development and assessment of disinfectant efficacy test methods for regulatory purposes. Am J Infect Control 2013;41 suppl 5: S72-S76.

10. Accident information data bank system. National Consumer Affairs Center of Japan website. http://www.jikojoho.go.jp/ai_national/search/aiscc09accidentsearchcondition.do. Published 2020. Accessed September 6, 2020. 